\title{
Hysterectomy for Cervical and Intraligamental Fibroids
}

\author{
Yuji Hiramatsu, MD, $\mathrm{PhD}^{1}$ \\ ${ }^{1}$ Department of Obstetrics and Gynecology, Okayama City General \\ Medical Center, Okayama, Japan \\ Surg J 2020;6(suppl S1):S2-S10.
}

Address for correspondence Yuji Hiramatsu, MD, PhD, Okayama City General Medical Center, 3-20-1 Kitanagase-Omotematchi, Kita-Ku, Okayama 700-8557, Japan (e-mail: kiki1063@cc.okayama-u.ac.jp).

\author{
Abstract \\ Keywords \\ - uterine cervical \\ fibroma \\ - intraligamental \\ fibroma \\ - hysterectomy \\ - retrograde \\ hysterectomy \\ - myomectomy
}

Hysterectomy for cervical and intraligamental fibroids is particularly likely to cause massive bleeding, ureteral/bladder injury, and intestinal damage. In such cases, preoperative evaluation is very important, and the way in which surgery proceeds should be based on the preoperative evaluation findings. In other words, before starting surgery, it is important to discuss what second and third methods to use if the first surgical method is unsuccessful. The main points to consider during surgery are expanding the operative field, approaching the operation from a site with weak adhesions, and performing applied techniques such as myomectomy and retrograde hysterectomy.

\section{Preoperative Examination and Preparation}

Blood tests, urine tests, electrocardiographic examination, and chest radiographs are performed in the same manner as for total hysterectomy. Deep vein thrombosis examination and drip infusion pyelography are also necessary.

Ultrasonography and magnetic resonance imaging (MRI) are performed to check the site and size of the fibroids, degree of adhesion with surrounding organs, and extent of bladder elevation. The levels of tumor markers, especially lactate dehydrogenase, are measured, and sarcomas are ruled out. The mobility of the uterus is checked by external and internal examination. If possible, autologous blood is preserved and ureteral stents are inserted.

\section{Informed Consent}

Because hysterectomy for cervical and intraligamental fibroids is a more difficult operation than usual total hysterectomy, the following points should be thoroughly explained to the patient: (1) the operation is difficult, (2) there is a risk of massive bleeding requiring a blood transfusion, and (3) ureter, bladder, and intestinal damage may occur.

\section{Surgical Steps}

The operation is based on usual abdominal simple total hysterectomy, and in most cases, it can be performed according to the method described below. However, difficult cases may also be encountered. In such situations, it is important to proceed with the surgery in a step-by-step manner from safe areas (i.e., areas with wide vision and weak adhesions).

1. Perform the laparotomy.

$\downarrow$

2. Inspect the position of the main ligaments and check the mobility of the uterus. $\downarrow$

3. Determine whether the usual abdominal simple hysterectomy is possible.

$\downarrow$

4. Clamp, cut, and ligate the round ligament. $\downarrow$

5. Clamp, cut, and ligate the ovarian ligament and fallopian tube (or infundibulopelvic ligament). $\downarrow$

6. Dissect the bladder.

$\downarrow$

7. Clamp, cut, and ligate the uterine artery. $\downarrow$

8. Clamp, cut, and ligate the sacrouterine ligament. $\downarrow$

9. Clamp, cut, and ligate the vesicouterine ligament. $\downarrow$

10. Cut and suture the vaginal wall. $\downarrow$
DOI https://doi.org/ 10.1055/s-0039-1698419. ISSN 2378-5128.
Copyright $\odot 2020$ by Thieme Medical Publishers, Inc., 333 Seventh Avenue, New York, NY 10001, USA. Tel: +1(212) 760-0888.
License terms

(®) $\odot \circledast$ 


\section{Perform hemostasis.}

$\downarrow$

12. Suture the bladder peritoneum, vaginal stump, and retroperitoneum at three points. $\downarrow$

13. Wash the abdominal cavity with physiological saline solution. Insert a drainage tube, if needed. $\downarrow$

14. Close the abdominal wall.

In many difficult cases, the procedure may not advance smoothly to steps 7 to 9, so the ligament must be cut from the easier side. An applied technique such as myomectomy or retrograde total hysterectomy is necessary in some cases.

\section{Explanation of Procedure}

Two representative cases are presented and the actual procedures are explained.

\section{Case 1}

Preoperative MRI revealed a large fibroid in the broad membrane reaching the cervix from the uterine body (-Fig. 1).

1. Laparotomy and inspection

The position of the main ligament is checked, the mobility of the uterus is evaluated, and whether usual abdominal simple hysterectomy can be performed is determined (-Fig. 2). For cervical fibroids that grow under the broad ligament, it is necessary to check whether the uterus is twisted.

2. Clamp, cut, and ligate the round ligament

The type of forceps to use for uterine traction is based on the size and degree of degeneration of the fibroma. First, the round ligament is clamped, cut, and ligated ( - Fig. 3). Next,

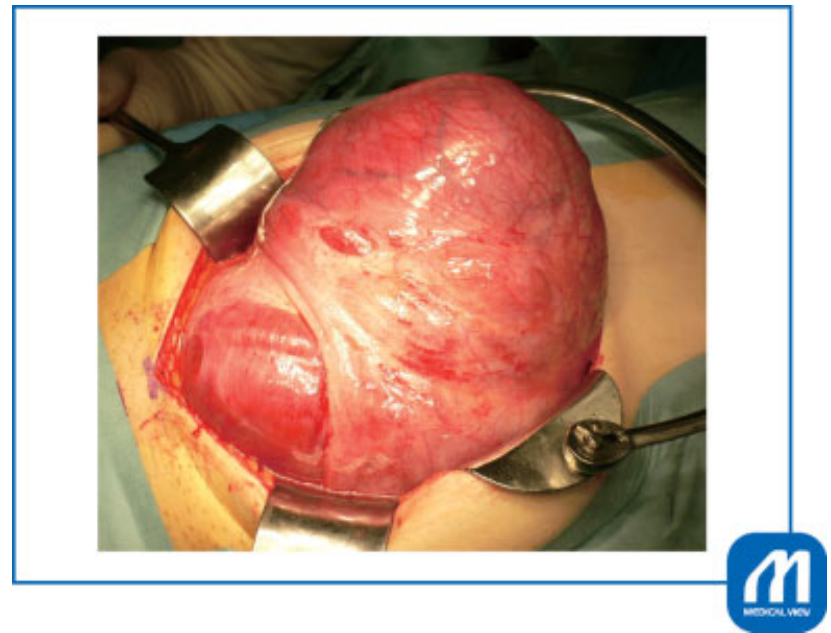

Fig. 2 Inspection: Check the position of the main ligaments, the mobility of the uterus, and whether usual abdominal simple hysterectomy is possible or not. (Reproduced with permission from Hiramatsu Y. In: Hiramatsu Y, Konishi I, Sakuragi N, Takeda S, eds. Mastering the Essential Surgical Procedures OGS Now, No.11. Uterine Myoma: How to Operate in These Cases? (Japanese). Tokyo: Medical View; 2012:70-79. Copyright @ Medical View.)

the surfaces of the intraligamental or cervical fibroids are exposed, and the fibroids are pulled out of the abdominal cavity. In this case, because a rigid fibroid was recognized, a myoma borer was used (-Fig. 4).

3. Clamp, cut, and ligate the ovarian ligament and fallopian tube (or infundibulopelvic ligament)

The ovarian ligament and fallopian tube are clamped, cut, and ligated, and the urinary bladder is dissected. In cases involving an anterior large cervical fibroma, it is sometimes impossible to obtain a sufficient field of vision, and sufficient dissection of the bladder cannot be performed.

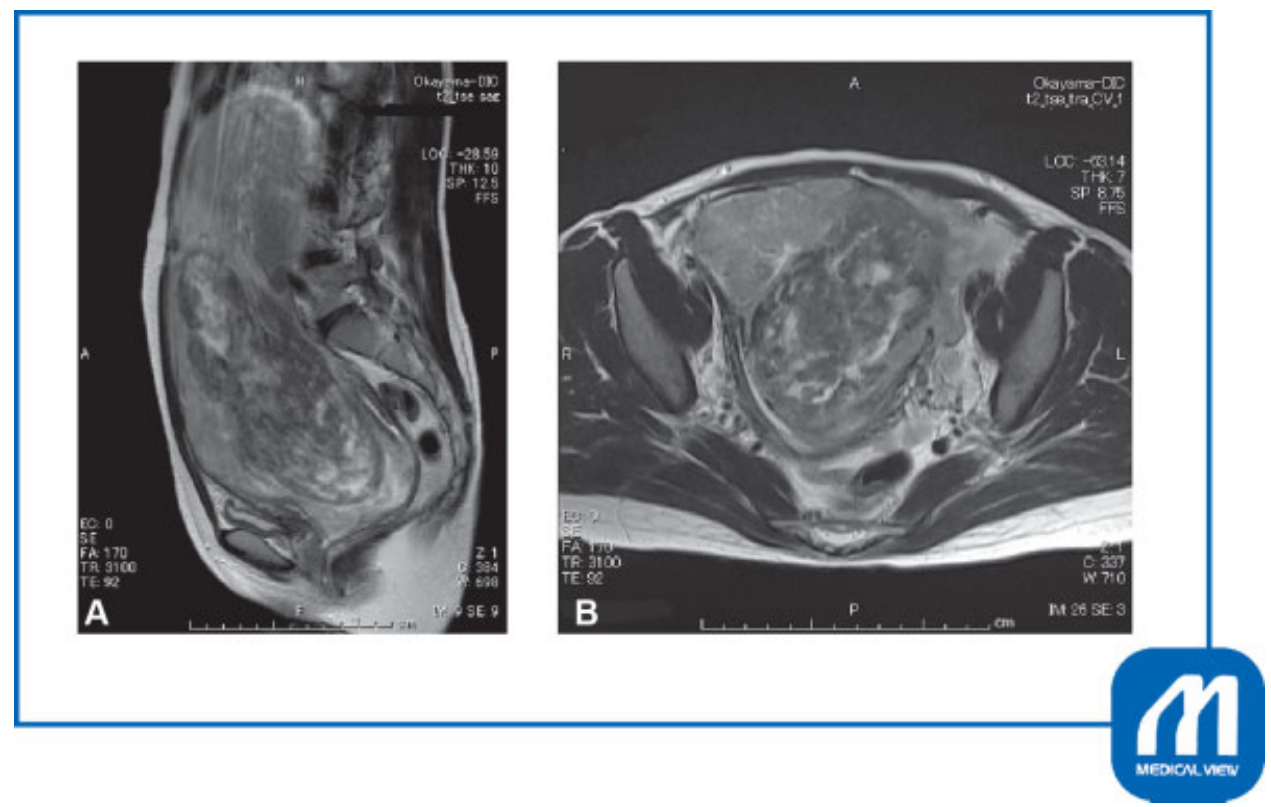

Fig. 1 Case1: Magnetic resonance imaging (MRI) T2 weighted: Preoperative MRI revealed a large fibroid in the broad membrane: (A) Sagittal and (B) horizontal. (Reproduced with permission from Hiramatsu Y. In: Hiramatsu Y, Konishi I, Sakuragi N, Takeda S, eds. Mastering the Essential Surgical Procedures OGS Now, No.11. Uterine Myoma: How to Operate in These Cases? (Japanese). Tokyo: Medical View; 2012:70-79. Copyright @ Medical View.) 


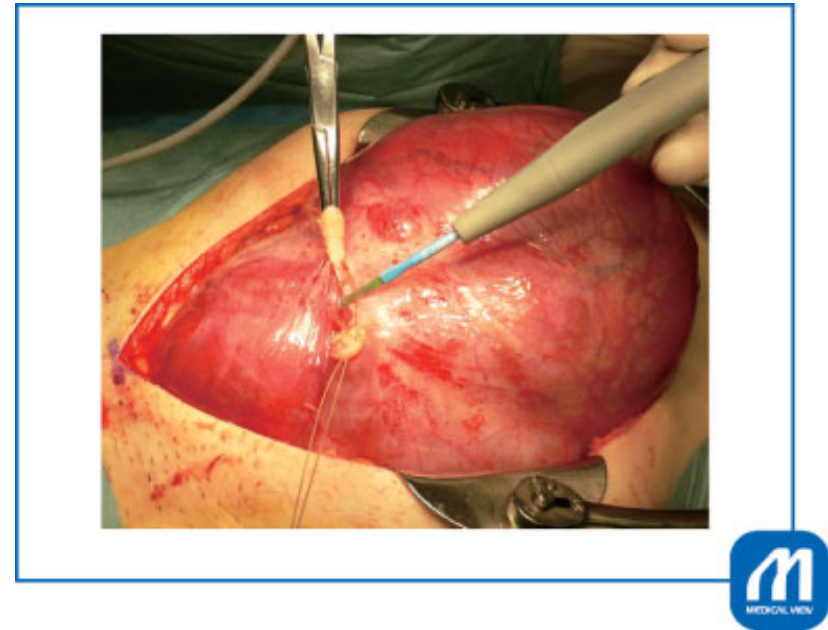

Fig. 3 Clamp, cut, and ligate the round ligament: The round ligament is clamped, cut, and ligated. (Reproduced with permission from Hiramatsu Y. In: Hiramatsu Y, Konishi I, Sakuragi N, Takeda S, eds. Mastering the Essential Surgical Procedures OGS Now, No.11. Uterine Myoma: How to Operate in These Cases? (Japanese). Tokyo: Medical View; 2012: 70-79. Copyright (c) Medical View.)

\section{Tips and Warnings}

Elevating the fibroid without bleeding is closely related to whether the subsequent operation is possible. The trick is to pull the myoma borer strongly and pull the fibroma up while rocking it back and forth and side to side. Because the ureter and large blood vessels run at the bottom of the fibroma nucleus, it is important to detach adhesions during this procedure only at sites that are directly visible.

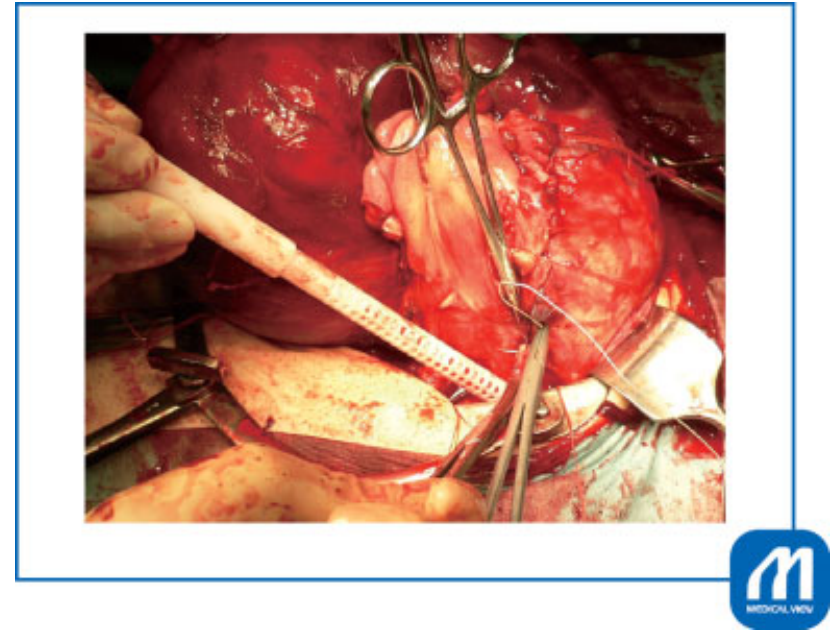

Fig. 5 Clamp, cut, and ligate the right uterine vessels: This procedure should be performed from the side that is easier to approach because the uterine cervix is enlarged. The fibroid must be treated while considering the possibility that the positions of the uterine artery and vein have become displaced by the large cervical fibroid. (Reproduced with permission from Hiramatsu Y. In: Hiramatsu Y, Konishi I, Sakuragi N, Takeda S, eds. Mastering the Essential Surgical Procedures OGS Now, No.11. Uterine Myoma: How to Operate in These Cases? (Japanese). Tokyo: Medical View; 2012: 70-79. Copyright (c) Medical View.)

\section{Pitfall}

The bladder is often stretched upward when a large anterior cervical fibroma is present. It is important to confirm the upper edge of the bladder by preoperative MRI examination. If the upper border of the bladder is not identified, 100 to $200 \mathrm{~mL}$ of physiological saline is injected through the balloon catheter into the bladder to facilitate visualization of the border.

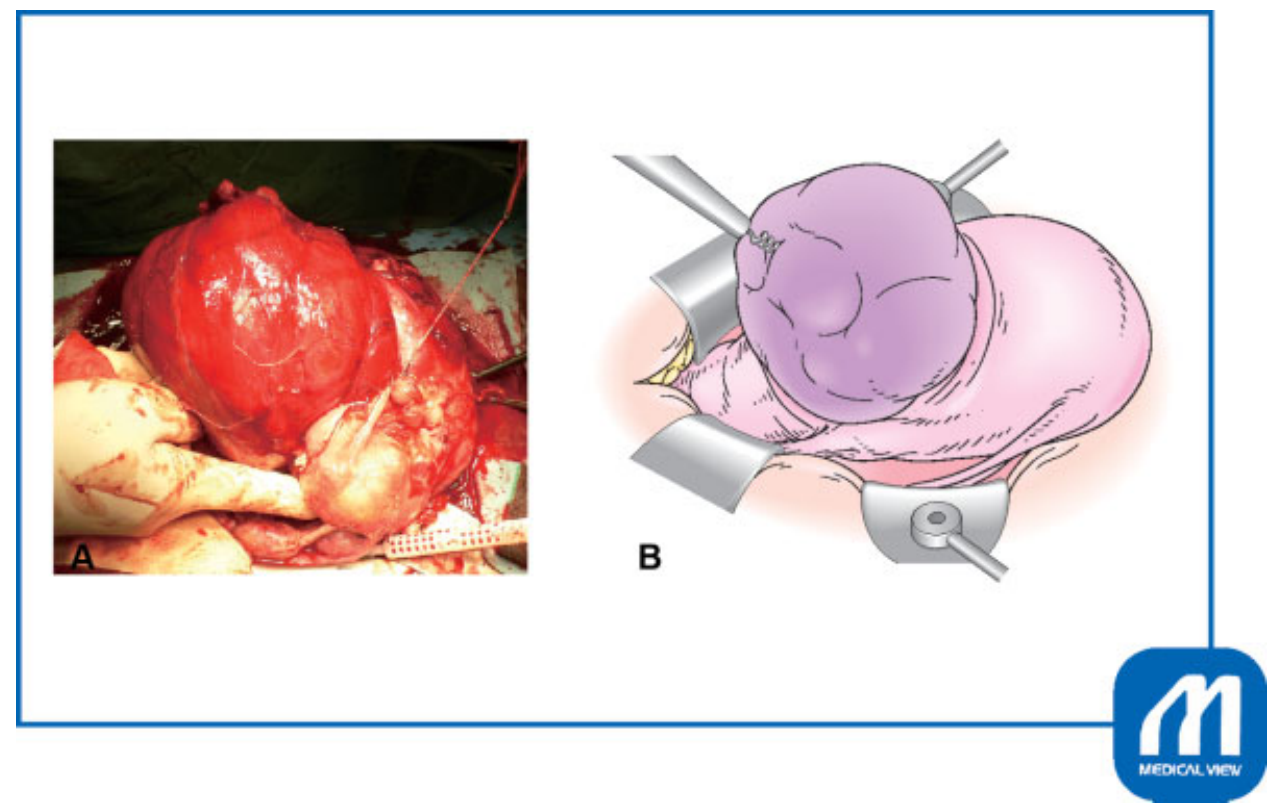

Fig. 4 Extraperitoneal extension of intraligamental fibroma and cervical fibroma: The surfaces of the intraligamental or cervical fibroids are exposed, and the fibroids are pulled out of the abdominal cavity. (Reproduced with permission from Hiramatsu Y. In: Hiramatsu Y, Konishi I, Sakuragi N, Takeda S, eds. Mastering the Essential Surgical Procedures OGS Now, No.11. Uterine Myoma: How to Operate in These Cases? (Japanese). Tokyo: Medical View; 2012: 70-79. Copyright @ Medical View.) 


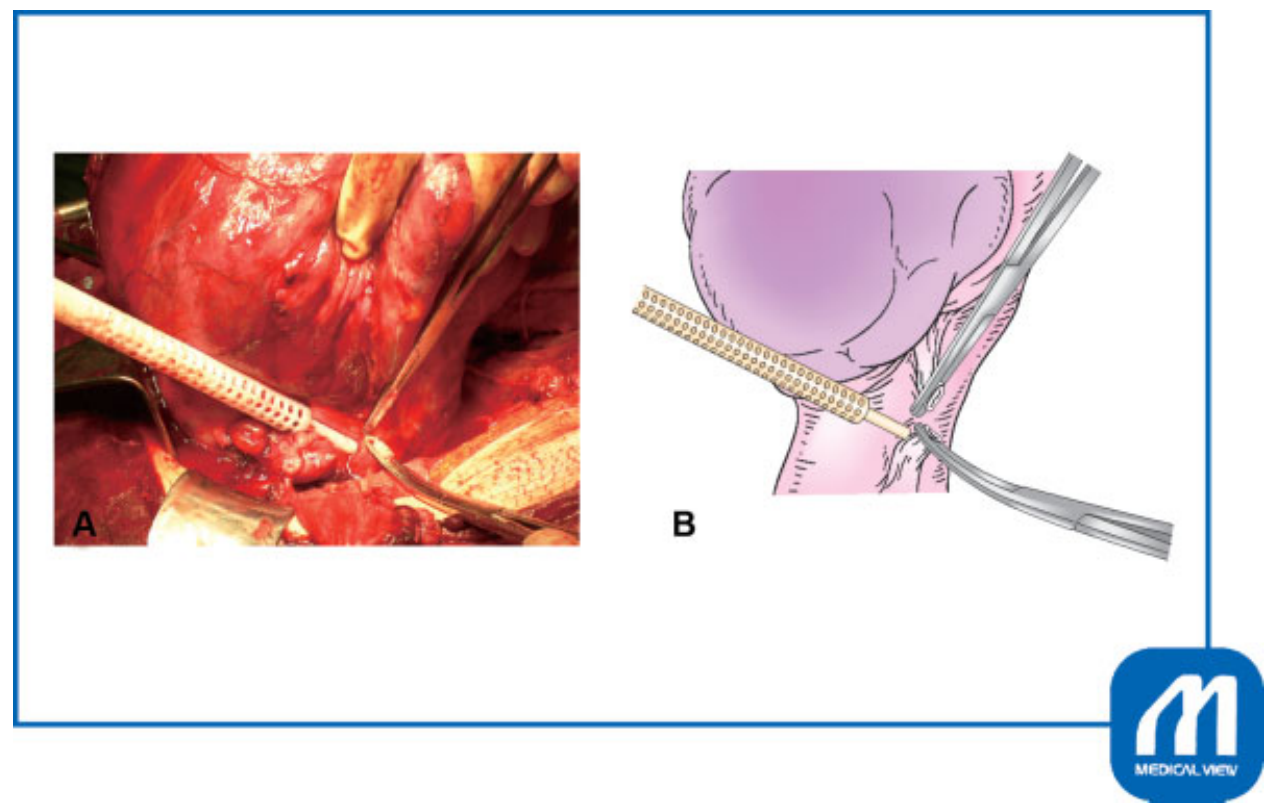

Fig. 6 Clamp, cut, and ligate the left uterine vessels: The figure shows the treatment of the left uterine artery and vein. (Reproduced with permission from Hiramatsu Y. In: Hiramatsu Y, Konishi I, Sakuragi N, Takeda S, eds. Mastering the Essential Surgical Procedures OGS Now, No.11. Uterine Myoma: How to Operate in These Cases? (Japanese). Tokyo: Medical View; 2012: 70-79. Copyright @ Medical View.)

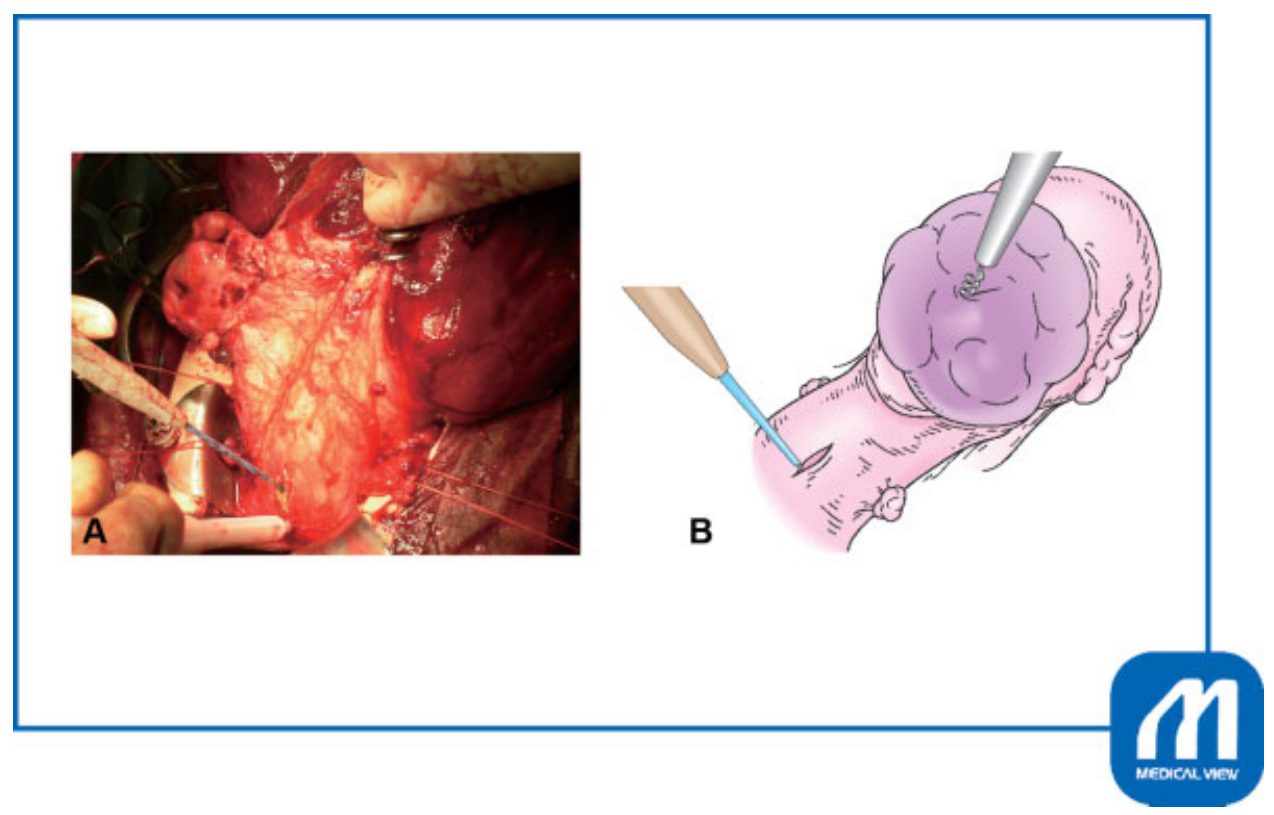

Fig. 7 Retrograde hysterectomy; Open the vagina: A 3- to 4-cm longitudinal incision is made in the center of the anterior cervical wall. The vaginal cavity is opened at the lower end, and the upper edge of the vagina is confirmed under direct vision. (Reproduced with permission from Hiramatsu Y. In: Hiramatsu Y, Konishi I, Sakuragi N, Takeda S, eds. Mastering the Essential Surgical Procedures OGS Now, No.11. Uterine Myoma: How to Operate in These Cases? (Japanese). Tokyo: Medical View; 2012: 70-79. Copyright @ Medical View.)

4. Clamp, cut, and ligate the uterine vessels

This procedure should be performed from the side that is easier to approach because the uterine cervix is enlarged (-Figs. 5 and $\mathbf{6}$ ). In addition, the fibroid must be treated while considering the possibility that the uterine cervix has expanded and the positions of the uterine artery and vein have become displaced.

5. Clamp, cut, and ligate the vesicouterine ligament

In usual simple total hysterectomy, ${ }^{1-3}$ the next procedure involves cutting of the sacrouterine ligament and vesicouter- ine ligament. In Case 1, however, a large fibroid extended from the posterior portio vaginalis and protruded into the vagina, and the border between the portio vaginalis and vagina could not be defined. Therefore, retrograde total hysterectomy was performed. The details of retrograde hysterectomy have been previously described. ${ }^{4-6}$

The uterus rises upward after cutting the bilateral uterine vessels, and the bladder is sufficiently dissected again. A 3- to 4-cm longitudinal incision is made in the center of the anterior cervical wall ( - Fig. 7). The vaginal cavity is opened at the lower 


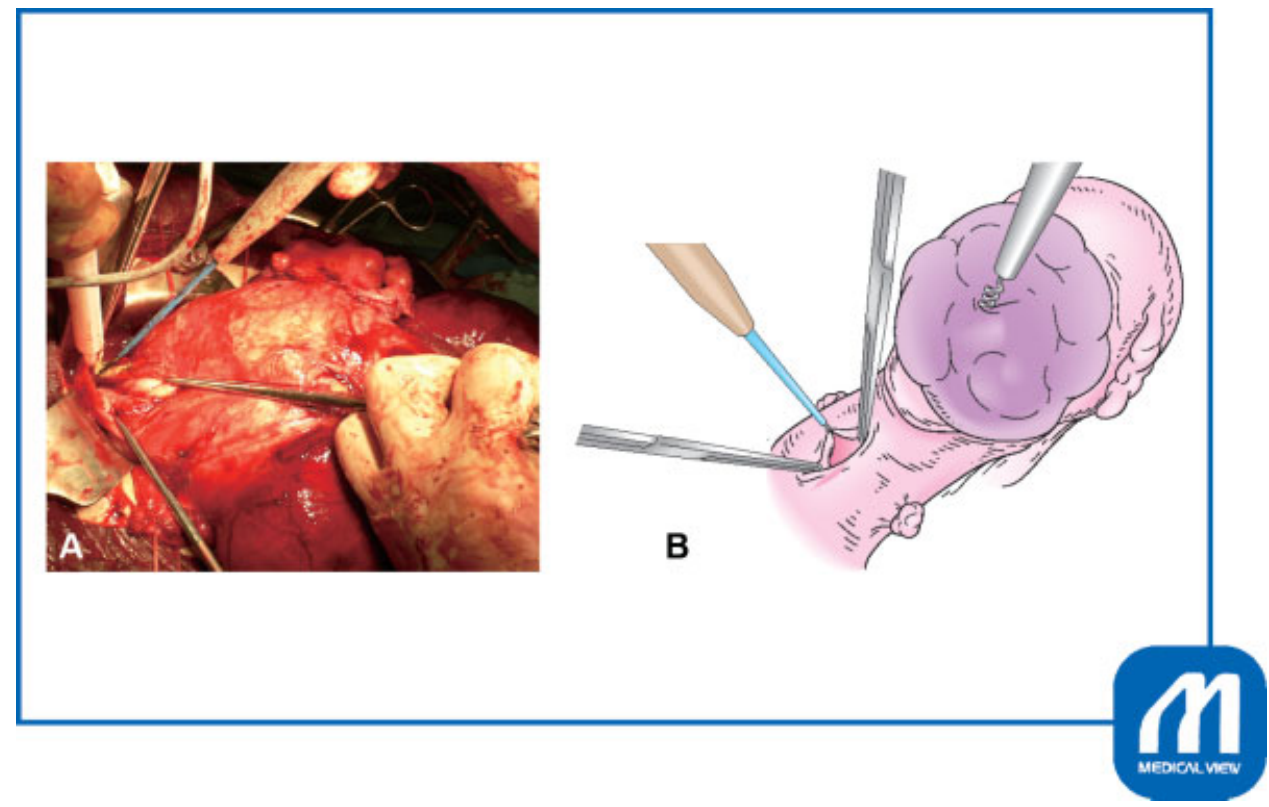

Fig. 8 Retrograde hysterectomy; Cut the anterior vaginal wall: The anterior vaginal wall is dissected from the upper end of the vagina to the adhered portion of the vesicouterine ligament. (Reproduced with permission from Hiramatsu Y. In: Hiramatsu Y, Konishi I, Sakuragi N, Takeda S, eds. Mastering the Essential Surgical Procedures OGS Now, No.11. Uterine Myoma: How to Operate in These Cases? (Japanese). Tokyo: Medical View; 2012: 70-79. Copyright @ Medical View.)

end, and the upper edge of the vagina is confirmed under direct vision. The anterior vaginal wall is dissected from the upper end of the vagina to the adhered portion of the vesicouterine ligament (-Fig. 8). Finally, the vesicouterine ligament is clamped, cut, and ligated (-Fig. 9).

\section{Points to Avoid Ureter Damage}

Cutting of the vesicouterine ligament is associated with a high risk of ureter damage. To avoid this damage, one leaf of a Heaney forceps is inserted into the vagina, placed in

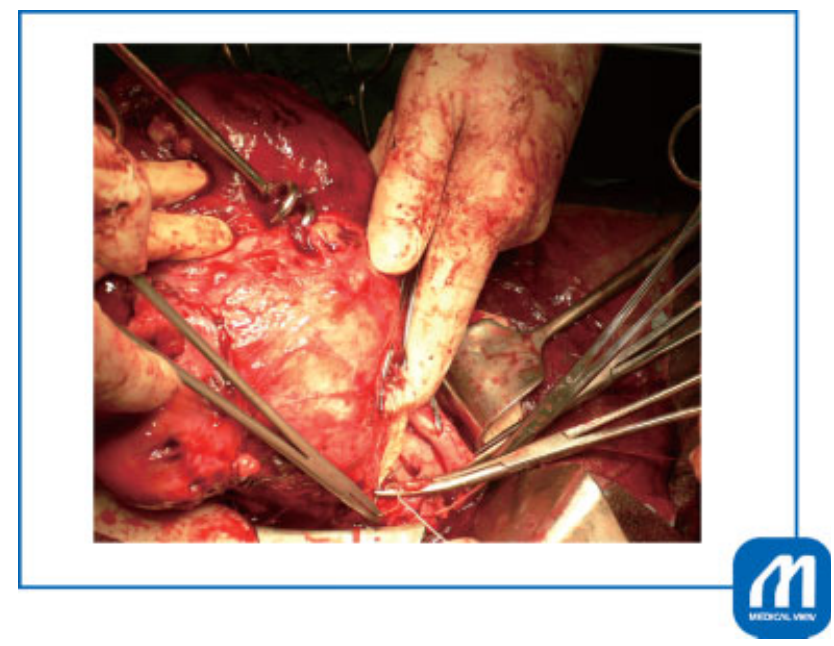

Fig. 9 Retrograde hysterectomy; Clamp, cut, and ligate the vesicouterine ligament: The vesicouterine ligament is clamped, cut, and ligated. How to use a Heaney forceps is important to avoid ureteral injury (see Tips and Warnings) (Reproduced with permission from Hiramatsu Y. In: Hiramatsu Y, Konishi I, Sakuragi N, Takeda S, eds. Mastering the Essential Surgical Procedures OGS Now, No.11. Uterine Myoma: How to Operate in These Cases? (Japanese). Tokyo: Medical View; 2012: 70-79. Copyright @ Medical View.) contact with the upper edge of the vagina, and clamped such that it faces diagonally forward of the uterus in the direction in which the vesicouterine ligament is adhered. Ureteral damage can be avoided by clamping the vesicouterine ligament at the upper edge of the vagina in the above-mentioned direction.

\section{Clamp, cut, and ligate the sacrouterine ligament}

Next, the sacrouterine ligament is clamped, cut, and sutured. A Heaney forceps is used to direct the sacrouterine ligament toward the diagonally posterior side of the uterus
Fig. 10 Disinfect the vaginal cavity: Disinfect the vaginal cavity after the treatments of bilateral vesicouterine and sacrouterine ligaments. (Reproduced with permission from Hiramatsu Y. In: Hiramatsu Y, Konishi I, Sakuragi N, Takeda S, eds. Mastering the Essential Surgical Procedures OGS Now, No.11. Uterine Myoma: How to Operate in These Cases? (Japanese). Tokyo: Medical View; 2012: 70-79. Copyright (c Medical View.) 


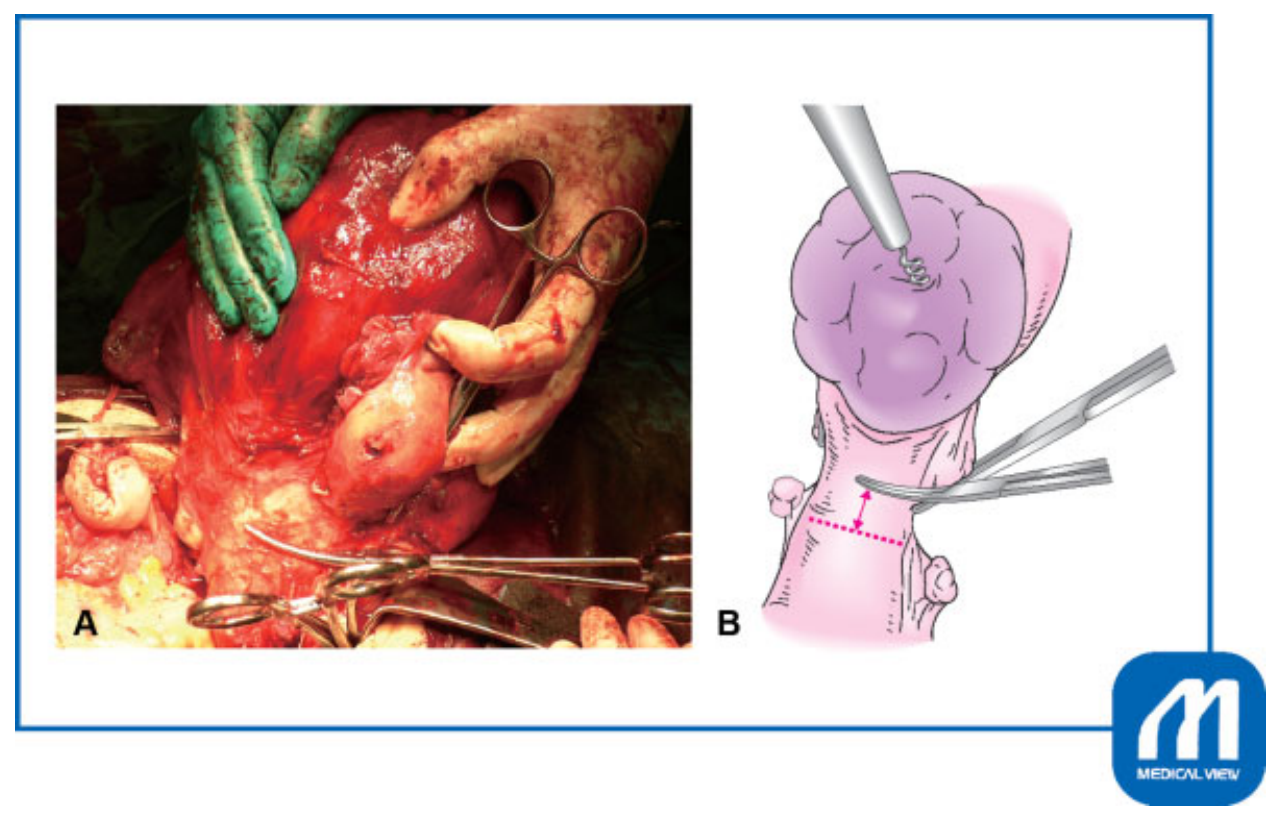

Fig. 11 Cut the vaginal wall: The upper edge of the vagina is indicated with a curved Pean forceps. If the vaginal wall is incised based on the palpation findings, the dotted line portion will be incised and the vagina will be overtaken by $\sim 3 \mathrm{~cm}$. By performing retrograde hysterectomy, the upper end of the vagina can be confirmed under direct vision, so shortening of the vagina can be prevented. (Reproduced with permission from Hiramatsu Y. In: Hiramatsu Y, Konishi I, Sakuragi N, Takeda S, eds. Mastering the Essential Surgical Procedures OGS Now, No.11. Uterine Myoma: How to Operate in These Cases? (Japanese). Tokyo: Medical View; 2012: 70-79. Copyright ( Medical View.)

and clamp it to the upper edge of the vagina. Next, because the fibroid is now raised from the posterior portio vaginalis that protruded into the vagina, it is grasped and pulled out to disinfect the vaginal cavity ( $\mathbf{- F i g . 1 0}$ ).

The upper edge of the vagina is indicated with a curved Pean forceps. However, if the vaginal wall is incised based on the palpation findings, the dotted line portion in - Fig. 11 will be incised and the vagina will be overtaken by $\sim 3 \mathrm{~cm}$. In this case (Case 1 ), because retrograde total hysterectomy was

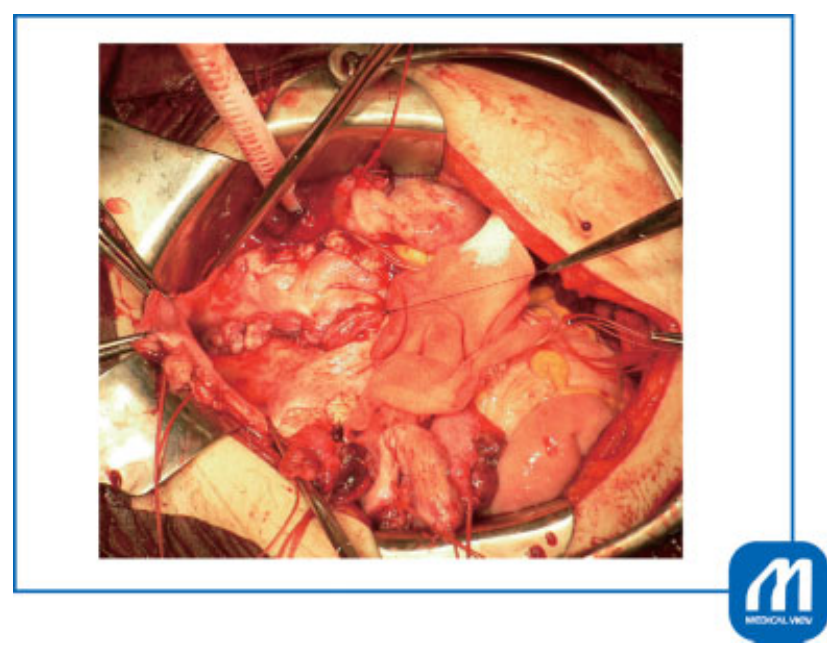

Fig. 12 Suture of the vaginal stump: The site at which the fibroid protruded into the vagina and adhered to the wall was repaired, and the vaginal cut end was sutured with absorbable thread. (Reproduced with permission from Hiramatsu Y. In: Hiramatsu Y, Konishi I, Sakuragi $\mathrm{N}$, Takeda S, eds. Mastering the Essential Surgical Procedures OGS Now, No.11. Uterine Myoma: How to Operate in These Cases? (Japanese). Tokyo: Medical View; 2012: 70-79. Copyright $\odot$ Medical View.) performed, it was possible to incise the posterior vaginal wall at the upper edge of the vagina under direct vision and prevent vaginal shortening (-Fig. 11).

The site at which the fibroid protruded into the vagina and adhered to the wall was repaired, and the vaginal cut end was sutured with absorbable thread ( - Fig. 12). Hemostasis was confirmed, intraperitoneal irrigation was performed, a drainage tube was inserted, and the abdomen was closed. The excised specimen is shown in - Fig. 13.

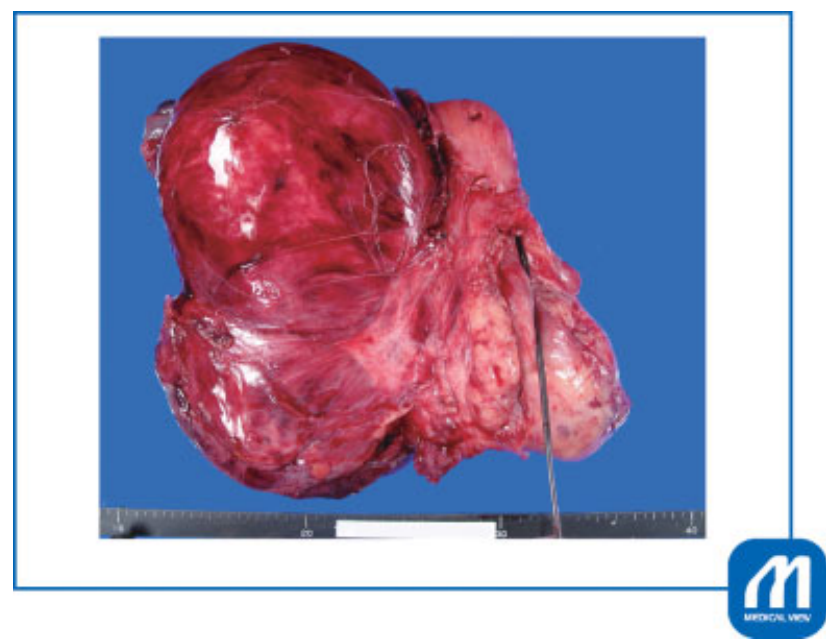

Fig. 13 Excised specimen: The uterine sonde indicates the position of the uterine cavity and cervical canal. It can be seen that large cervical fibroids had developed into the vagina and the retroperitoneum. (Reproduced with permission from Hiramatsu Y. In: Hiramatsu Y, Konishi I, Sakuragi N, Takeda S, eds. Mastering the Essential Surgical Procedures OGS Now, No.11. Uterine Myoma: How to Operate in These Cases? (Japanese). Tokyo: Medical View; 2012: 70-79. Copyright $\odot$ Medical View.) 


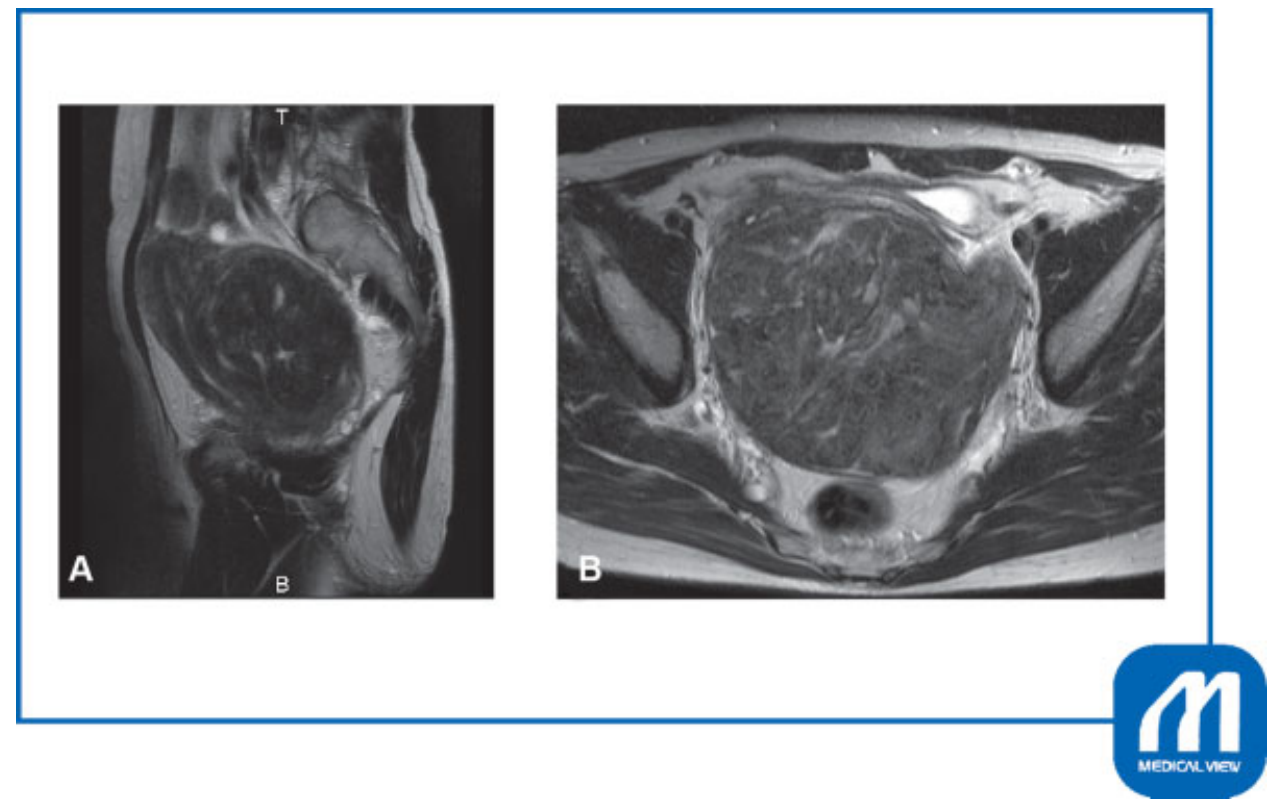

Fig. 14 Case2: Magnetic resonance imaging (MRI) T2 weighted: Preoperative MRI showed an 11-cm uterine fibroid in the left posterior cervical wall, fully occupying the pelvic floor. (A) Sagittal and (B) horizontal (Reproduced with permission from Hiramatsu Y. In: Hiramatsu Y, Konishi I, Sakuragi N, Takeda S, eds. Mastering the Essential Surgical Procedures OGS Now, No.11. Uterine Myoma: How to Operate in These Cases? (Japanese). Tokyo: Medical View; 2012: 70-79. Copyright @ Medical View.)

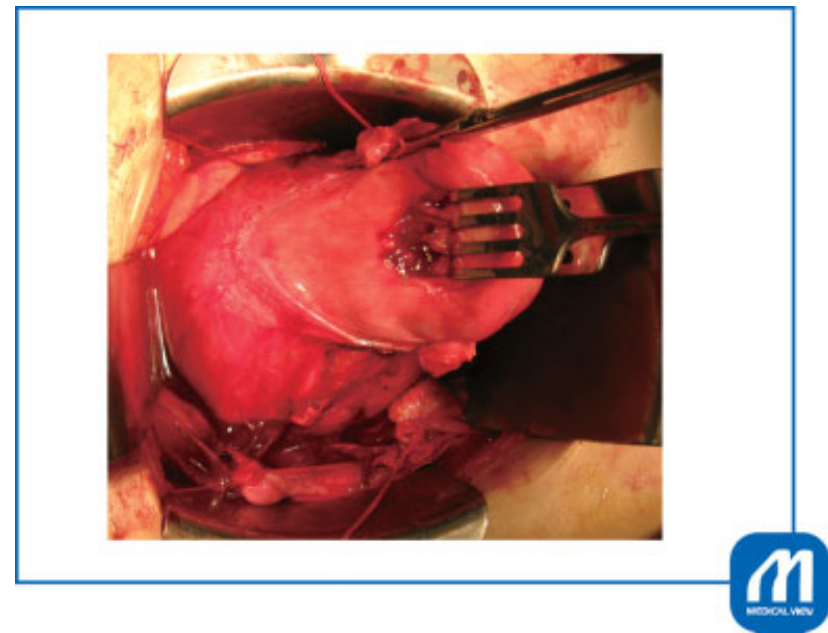

Fig. 15 Findings at laparotomy: It was difficult to secure a sufficient operation field anterior and posterior to the uterus, and usual simple total hysterectomy was impossible. (Reproduced with permission from Hiramatsu Y. In: Hiramatsu Y, Konishi I, Sakuragi N, Takeda S, eds. Mastering the Essential Surgical Procedures OGS Now, No.11. Uterine Myoma: How to Operate in These Cases? (Japanese). Tokyo: Medical View; 2012: 70-79. Copyright (c) Medical View.)

\section{Tips and Warnings}

The main points to consider in Case 1 are as follows.

1. The ligaments were cut from the side on which the view was wide and the operation was technically easy to perform, helping to avoid bleeding and complications.

2.

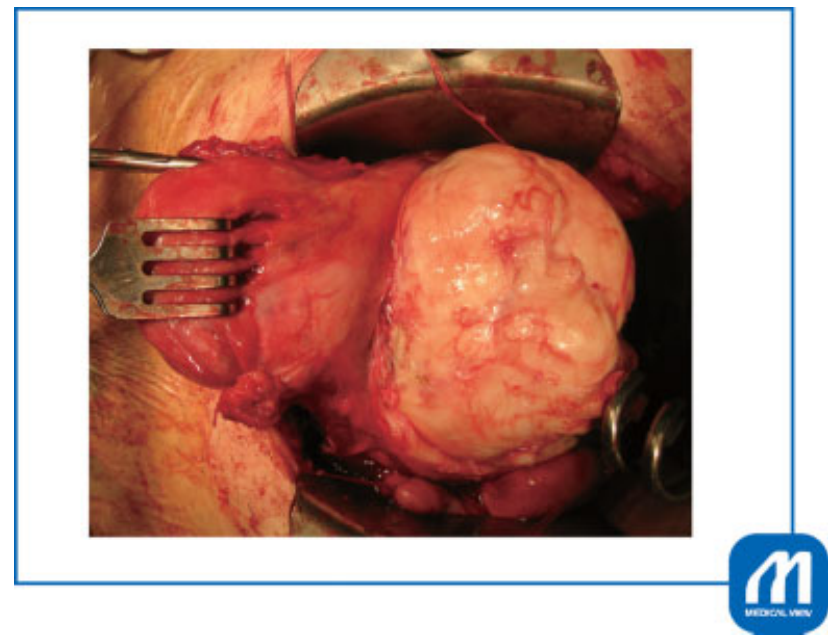

Fig. 16 Enucleation of the posterior wall cervical fibroma: To secure a sufficient operation field, enucleation of the posterior wall cervical fibroma was performed first. (Reproduced with permission from Hiramatsu Y. In: Hiramatsu Y, Konishi I, Sakuragi N, Takeda S, eds. Mastering the Essential Surgical Procedures OGS Now, No.11. Uterine Myoma: How to Operate in These Cases? (Japanese). Tokyo: Medical View; 2012: 70-79. Copyright @ Medical View.)

The cervical and retroperitoneal fibroma was lifted while pulling it and shaking it back and forth and side to side.

3. Because the border between the uterine cervix and the vagina could not be identified, retrograde total hysterectomy was performed to prevent vaginal shortening. 


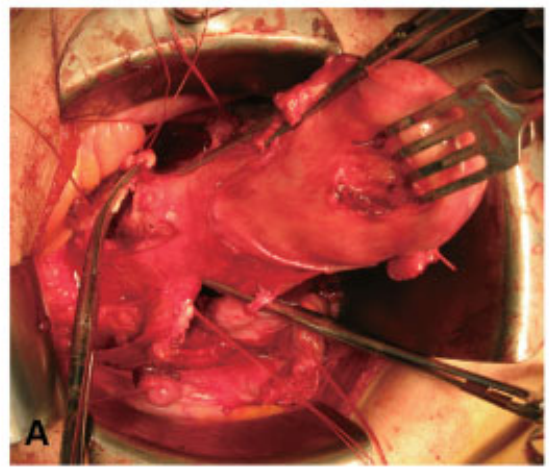

B

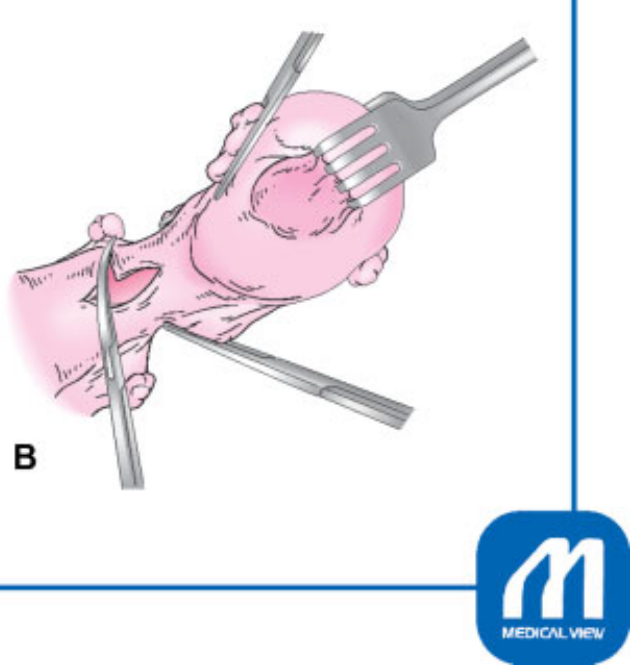

Fig. 17 Retrograde hysterectomy; Open the vagina: The large posterior uterine cervical fibroma stretched the vaginal wall, and it was impossible to identify the border between the portio vaginalis and vagina. Therefore, retrograde total hysterectomy was performed. (Reproduced with permission from Hiramatsu Y. In: Hiramatsu Y, Konishi I, Sakuragi N, Takeda S, eds. Mastering the Essential Surgical Procedures OGS Now, No.11. Uterine Myoma: How to Operate in These Cases? (Japanese). Tokyo: Medical View; 2012: 70-79. Copyright @ Medical View.)

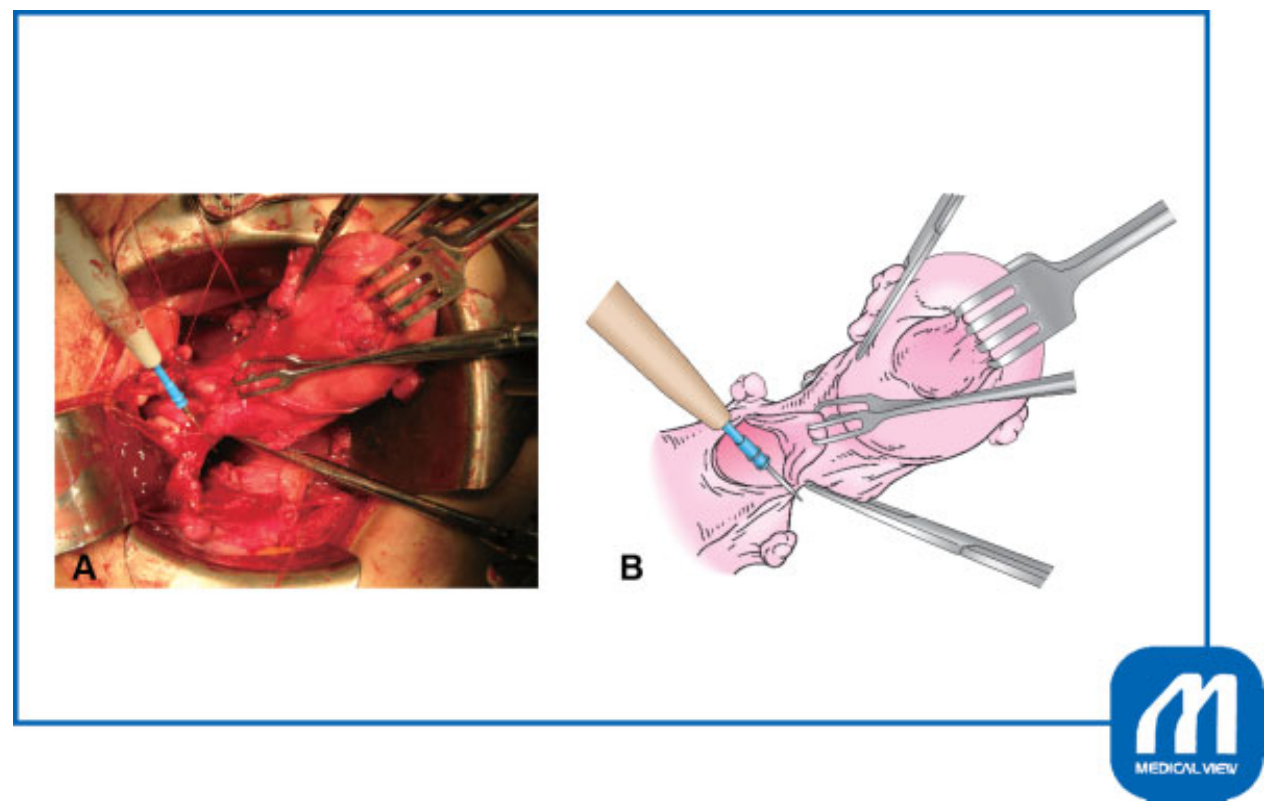

Fig. 18 Retrograde hysterectomy; Cut the posterior vaginal wall: Grasp the thinly stretched portiovaginalis with a forceps, turn it over, and cut the upper edge of posterior vaginal wall under direct vision. (Reproduced with permission from Hiramatsu Y. In: Hiramatsu Y, Konishi I, Sakuragi N, Takeda S, eds. Mastering the Essential Surgical Procedures OGS Now, No.11. Uterine Myoma: How to Operate in These Cases? (Japanese). Tokyo: Medical View; 2012: 70-79. Copyright @ Medical View.)

\section{Case 2}

MRI showed an 11-cm uterine fibroid in the posterior cervical wall, fully occupying the pelvic floor ( - Fig. 14). It was difficult to secure a sufficient operation field anterior and posterior to the uterus, and usual simple total hysterectomy was impossible (-Fig. 15). Therefore, enucleation of the posterior wall cervical fibroma was performed first. A myoma borer was implanted into the fibroma node and pulled strongly, a scaph- oid incision was made in the surface of fibroma, and the fibroma was enucleated (-Fig. 16).

\section{Tips and Warnings}

A wide view of a posterior cervical fibroma is difficult to obtain, and bleeding readily occurs because it is surrounded by the uterine arteries and veins. Therefore, 


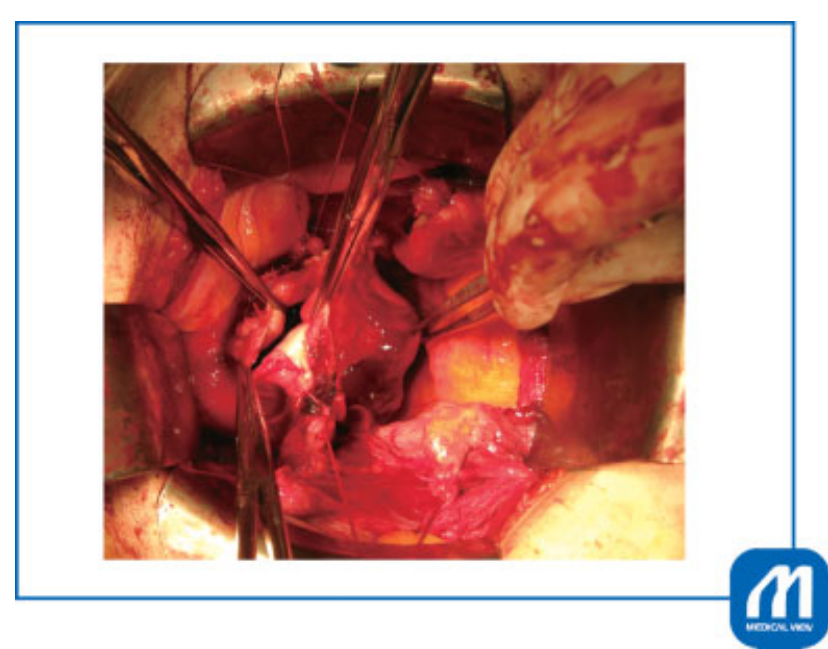

Fig. 19 Closure of vaginal stump: The vaginal stump is sutured with an absorbable thread and hemostasis on the fibroma enucleation site is performed. (Reproduced with permission from Hiramatsu Y. In: Hiramatsu Y, Konishi I, Sakuragi N, Takeda S, eds. Mastering the Essential Surgical Procedures OGS Now, No.11. Uterine Myoma: How to Operate in These Cases? (Japanese). Tokyo: Medical View; 2012: 70-79. Copyright @ Medical View.)

enucleation at the correct layer is essential. Strong pulling makes it easier to identify the correct layer to enucleate the fibroma and reduces the amount of bleeding because of pressure hemostasis during the operation (-Fig. 16). If enucleation is performed at the correct layer, almost no bleeding occurs. Vasopressin injection is also useful for reducing the bleeding volume.

\section{Pitfall}

Injection of vasopressin (Pitressin) is useful for decreasing the bleeding volume. One ampule of vasopressin (20 units, $1 \mathrm{~mL}$ ) is dissolved in $100 \mathrm{~mL}$ of physiological saline and injected. Potential adverse effects may be severe and include hypotension, pulmonary edema, cardiac arrest, and urinary volume reduction.

In Case 2, the large posterior uterine cervical fibroma stretched the vaginal wall, and it was impossible to identify the border between the portio vaginalis and vagina. Therefore, retrograde total hysterectomy was performed. The precise methods of retrograde hysterectomy were described in Case
1 and in a previous report, ${ }^{3-5}$ therefore, the procedure in Case 2 is briefly explained in the figure legends (-Figs. 17-19).

\section{Tips and Warnings}

The main points to consider in Case 2 are as follows.

1. The large posterior cervical fibroma was first enucleated to secure the operative field.

2. Even after enucleation of the fibroma, the location of the portio vaginalis was unclear by palpation. Therefore, retrograde total hysterectomy was performed.

With these two techniques, hysterectomy was safely performed with only a small amount of bleeding.

Conflict of Interest

None.

\section{Acknowledgment}

We thank Angela Morben, DVM, ELS, from Edanz Group (www.edanzediting.com/ac), for editing a draft of this manuscript.

\section{References}

1 Hiramatsu Y. Basic procedure 1. In: Hiramatsu Y, Konishi I, Sakuragi N, Takeda S, eds. Mastering the Essential Surgical Procedures OGS Now, No.2 Total Abdominal Hysterectomy (Japanese). Tokyo: Medical View; 2010:42-55

2 Hiramatsu Y. Basic Standard Procedure of Abdominal Hysterectomy: Part 1 Precision Surgery in Obstetrics and Gynecology, 1-9, 2019 DOI: https://doi.org/10.1055/s-0039-1678575. ISSN 2378-5128

3 Hiramatsu Y, Sekiba K. Abdominal simple hysterectomy (extrafascial method). In: Practical Methods for Hysterectomy. Tokyo: Nankodo; 1997:15-43

4 Hiramatsu Y. Application of retrograde abdominal hysterectomy in debulking surgery of epithelial ovarian cancer. Obstet Gynecol (Japanese) 2009;76:409-415

5 Hiramatsu Y. Basic procedure 1. In Hiramatsu Y, Konishi I, Sakuragi N, Takeda S, eds. Mastering the Essential Surgical Procedures, OGS Now, No.2 Application of Retrograde Abdominal Hysterectomy. Tokyo: Medical View; 2010:162-169

6 Yuji Hiramatsu. Retrograde Abdominal Hysterectomy Precision Surgery in Obstetrics and Gynecology DOI: https://doi.org/ 10.1055/s-0039-1683919. ISSN 2378-5128. 